\title{
Neonatal endothelin-1 concentrations in term infants
}

\author{
P D Macdonald, R D Paton, R W Logan
}

\begin{abstract}
Endothelin-1 concentrations were studied in 30 term infants during the first week of life using a radioimmunoassay kit. A neonatal reference range was established $(7 \cdot 5-25 \cdot 7 \mathrm{pmol} / \mathrm{)})$. No significant relation with age, sex, gestation, or birth weight was found.

(Arch Dis Child 1994; 70: F223-F224)
\end{abstract}

Endothelin-1 is a 21 amino acid vasoconstrictor peptide produced by endothelial cells. It is formed by cleavage of a 203 amino acid precursor molecule producing the 38 amino acid big endothelin-1. Endothelin converting enzyme acts on this to produce endothelin-1. ${ }^{12}$

The endothelin-1 gene is expressed widely in the systemic and pulmonary vasculature and endothelin may play a part in the normal physiological vascular changes at birth and possibly also in certain pathological states. Normal neonatal concentrations have not been defined and the purpose of this study is to establish a reference range in essentially healthy infants in the first week of life.

\section{Patients and methods}

We studied healthy term infants with physiological jaundice requiring blood samples for the determination of bilirubin. Infants were only enrolled if they had a normal delivery with a five minute Apgar score of 8-10, were clinically well, feeding normally, and not requiring phototherapy. The study protocol was approved by the local ethics committee and individual parental consent was obtained.

The blood samples were obtained by inserting a needle into a hand vein and allowing a free flow of blood into a lithium-heparin bottle. The bilirubin sample was obtained first and if blood flow continued freely a further $2 \mathrm{ml}$ sample was obtained for the study. Samples were obtained and processed from 30 infants (18 girls and 12 boys) of birth weight ranging from 2030 to $4730 \mathrm{~g}$ (mean (SD) 3520 (510) g), gestation from 36 to 42 weeks (mean (SD) $39.2(1.4)$ weeks), and age at the time of sampling from 24 to 137 hours (mean (SD) $65 \cdot 4(26 \cdot 4)$ hours). Bilirubin concentrations at the time of sampling ranged from 99 to 321 $\mu \mathrm{mol} / \mathrm{l}$ (mean (SD) $196(57 \cdot 8) \mu \mathrm{mol} / \mathrm{l})$.

After collection, samples were promptly centrifuged $\left(2000 \mathrm{~g}\right.$ at $4^{\circ} \mathrm{C}$ for 10 minutes) and separated, and the plasma was stored at $-70^{\circ} \mathrm{C}$ until analysis. Endothelin was extracted using $500 \mathrm{mg} \mathrm{C} 2$ columns (Amersham Life Science, RPN 1913) and assayed using an endothelin-1 specific radioimmunoassay system (Amersham Life Science, RPA 555) following the standard Amersham protocol. This assay is highly specific for the biologically active form of endothelin-1.

Cross reactivity with the active structurally similar peptides endothelin-2 and endothelin-3 and the inactive precursor big endothelin-1 are 144,52 , and $0.4 \%$ respectively.

\section{Results}

Using probability paper the results were plotted against the calculated centile and a good linear fit was demonstrated, supporting a normal distribution. Endothelin values ranged from 5.8 to $26.1 \mathrm{pmol} / \mathrm{l}$ (mean (SD) 16.6 $(4.44) \mathrm{pmol} / \mathrm{l})$; the scatter of results is illustrated in the figure. We have taken the $95 \%$ confidence limits of 7.5 to $25.7 \mathrm{pmol} / \mathrm{l}$ as our reference range (mean $\pm 2.04 \mathrm{SD}$ ). Endothelin results were plotted against gestational age, birth weight, and bilirubin concentration; no correlation with any of these variables was found. The figure compares postnatal age with endothelin-1 concentration; the correlation was weak and not significant at the $5 \%$ level $\left(r^{2}=0 \cdot 12 ; 0 \cdot 1>\mathrm{p}>0 \cdot 05\right)$.

The results for male and female infants were calculated separately. The values for the 12 male infants (mean (SD) 18.1 (3.20)) were slightly higher than those for the 18 girls (mean (SD) $15.6(4.94))$. This difference was evaluated using an unpaired $t$ test $(\mathrm{p}>0 \cdot 1)$ and a Wilcoxon rank sum test $(0 \cdot 1>p>0 \cdot 05)$.

\section{Discussion}

The endothelin-1 gene is expressed widely throughout the circulation and specific high affinity endothelin-1 binding sites have been found in many organs, ${ }^{3}$ suggesting multiple possible roles for the peptide. Animal and

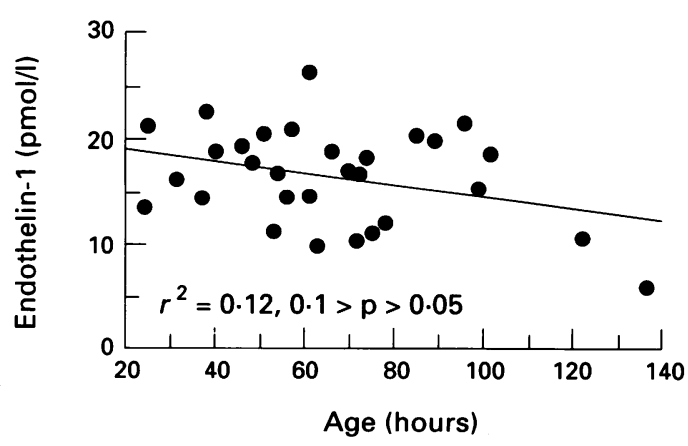

Scatter plot of endothelin-1 concentrations (pmoll) plotted against postnatal age (hours) with superimposed regression line. 
human tissue experiments have demonstrated potent constrictor actions on pulmonary arterial and bronchial smooth muscle. ${ }^{45}$ Interesting possibilities arise for both physiological and pathological roles for endothelin in the neonatal period. Many areas might be considered worthy of study - for example, ductal closure or persistent patency, constriction of umbilical vessels, necrotising enterocolitis, neonatal pulmonary hypertension, or asphyxial damage.

This study provides a neonatal reference range for endothelin-1 in term infants using a readily available assay kit. We found no correlation with birth weight or gestational age. The correlation with postnatal age was weak and like the difference between male and female infants was not statistically significant. The neonatal endothelin-1 concentrations that we measured are substantially higher than previously quoted cord blood concentrations. ${ }^{6}$ The assay used only detects the biologically active forms of endothelin and not the precursor molecule. The relatively high concentrations in these healthy infants suggests the presence of active physiological roles for endothelin in the neonatal period. To interpret results in pathological situations we require more knowledge of the normal concentrations and actions of endothelin. This neonatal reference range provides a baseline against which to compare endothelin-1 values in pathological states to recognise possible aetiological roles for endothelin.

This study was funded by a grant from the Greater Glasgow Health Board Research Support Group.

1 Yanagisawa M, Kurihara H, Kimura S, et al. A novel potent vasoconstrictor peptide produced by vascular endothelial cells. Nature 1988; 332: 411-5.

2 Yanagisawa M, Masaki T. Endothelin, a novel endothelium derived peptide. Biochem Pharmacol 1989; 39: 1877-83. 3 Davenport AP, Nunez DJ, Hall JA, Kaumann AJ, Brown MJ. Autoradiographical localisation of binding sites for porcine [125] ]endothelin-1 in humans, pigs and rats. Functiona relevance in humans. $f$ Cardiovasc Pharmacol 1989. 13: S166-70.

4 Lippton HL, Ohlstein EH, Summer WR, Hyman AL. Analysis of responses to endothelin in the rabbit pulmonary and systemic vascular beds. $₹$ Appl Physiol 1991; 70: 331-41.

5 MacKay KO, Black JL, Armour CL. The mechanism of action of endothelin in human lung. Br $\mathcal{F}$ Pharmacol 1991;

6 Nakamura T, Kasai K, Konuma S, et al. Immunoreactive endothelin concentrations in maternal and fetal blood. Life Sci 1990; 46: 1045-50. 